\title{
BUDAYA PATRIARKI DALAM FILM KARTINI (2017) KARYA HANUNG BRAMANTYO
}

\author{
Karkono $^{1}$, Justitia Maulida ${ }^{2}$, dan Putri Salma Rahmadiyanti ${ }^{3}$ \\ 1,2,3 Jurusan Sastra Indonesia, Fakultas Sastra, Universitas Negeri Malang \\ Email: karkonosupadiputra@yahoo.com¹, justimaulida@gmail.com², salmaput1999@gmail.com³
}

\begin{abstract}
Abstrak
Penelitian ini bertujuan untuk mendeskripsikan budaya patriarki, perlawanan tokoh Kartini terhadap budaya patriarki, dan reaksi tokoh lain terhadap perlawanan Kartini dalam film Kartini. Adapun teori yang digunakan dalam penelitian ini adalah teori sastra feminis dan semiotika. Sumber data dalam penelitian kualitatif ini adalah film Kartini dengan teknik pengumpulan data observasi atau pengamatan dan studi literatur. Adapun teknik analisis data dilakukan sejak, sebelum, selama, dan setelah proses penelitian. Hasil penelitian ini berupa kumpulan deskripsi budaya patriarki, perlawanan tokoh Kartini terhadap budaya patriarki, dan reaksi tokoh lain terhadap perlawanan Kartini dalam film Kartini.
\end{abstract}

Kata kunci: Patriarki, Kartini, Budaya Jawa.

\section{PATRIARCHY CULTURE IN KARTINI FILM (2017) BY HANUNG BRAMANTYO}

\author{
Karkono $^{1}$, Justitia Maulida ${ }^{2}$, dan Putri Salma Rahmadiyanti ${ }^{3}$ \\ ${ }^{1,2,3}$ Indonesian Literature Department, Faculty of Letters, State University of Malang \\ Email: karkonosupadiputra@yahoo.com ${ }^{1}$, justimaulida@gmail.com ${ }^{2}$, salmaput1999@gmail.com ${ }^{3}$
}

\begin{abstract}
This study aims to describe the patriarchal culture, Kartini's resistance to patriarchal culture, and other people's reaction to Kartini's resistance contained in the Kartini film. The theory used in this research is feminist literary theory and semiotics. The source of data in this qualitative research is Kartini film with observation or observation data collection techniques and literature studies. The data analysis techniques were carried out since, before, during and after the research process. The results of this research are a collection of descriptions of patriarchal culture, Kartini's resistance to patriarchal culture, and other people's reaction to Kartini's resistance contained in the Kartini film.
\end{abstract}

Keywords: Patriarchy, Kartini, Javanese Culture.

\section{PENDAHULUAN}

Film merupakan salah satu bentuk dari komunikasi massa. Film bersifat audio visual. Film merekam realitas yang berkembang dalam masyarakat kemudian memproyeksikan ke layar lebar. Kemampuan film dalam menciptakan gambar dan suara dapat menjangkau berbagai segmen sosial dan berpotensi untuk mempengaruhi 
khalayaknya. Film selalu mempengaruhi dan membentuk masyarakat berdasarkan muatan pesan dibaliknya (Sobur, 2013:127).

Film menjadi alat propaganda yang cukup efektif untuk memasukkan ideologi dan ajaran tertentu dalam masyarakat. Dilansir dari tirto.id, sejumlah studi di bidang neurosains membuktikan bahwa film memang dapat mengendalikan sentimen orang.Melaluifunctional magnetic resonance imaging (FMRI), para ilmuwan dari New York University mengetahui reaksi otak manusia terhadap adegan, warna, dan musik latar dalam film; dan hal itu menjadikan film-film yang mempunyai tujuan tertentu, misalnya menakut-nakuti, sukses menancapkan pengaruh dan pesan di kepala para penontonnya. Pesan-pesan atau nilai-nilai yang terkandung dalam film dapat mempengaruhi penonton baik secara kognitif, afektif,dan konatif.

Graeme Turner (dalam Sobur, 2013:127) menolak untuk melihat film sebagai refleksi masyarakat. Bagi Turner, makna film sebagai representasi realitas masyarakat berbeda dengan film sekadar sebagai refleksi realitas. Sebagai refleksi realitas, film sekadar memindahkan realitas ke layar tanpa mengubah realitas itu. Sementara itu, sebagai representasi realitas, film membentuk dan menghadirkan kembali realitas berdasarkan kode-kode, konvensi-konvensi dan ideologi dari kebudayaan.

Alkhajar (2013:190) mengungkapkan bahwa film bukanlah sebuah entitas yang netral dan bebas nilai. Film tidak pula lahir dari ruang kosong. Lebih dari itu, film merupakan media yang efektif dalam membawa pesan-pesan yang memang dilekatkan dan ditanamkan padanya untuk kemudian disampaikan kepada segenap penontonnya.

Budaya patriarki sebagai manifestasi adat istiadat masyarakat Jawa sering diangkat sebagai subtema layar lebar. Perempuan dalam konteks budaya patriarki sering dianggap sebagai pihak inferior, sedangkan laki-laki sebaliknya. Pernyataan tersebut didukung pendapat Raharjo (dalam Anggreni, 2015:57) bahwa peran dan status wanita telah diciptakan oleh budaya. Citra seorang wanita seperti yang telah dianggap oleh budaya, antara lain, lemah lembut, penurut, tidak membantah, dan tidak boleh "melebihi" laki-laki. Peran yang diidealkan bagi wanita, misalnya mengurus rumah tangga, pendukung suksesnya pekerjaan suami, serta istri yang penurut dan ibu dari anak-anaknya. Sedangkan citra yang dibuat untuk laki-laki antara lain, "serba tahu", menjadi panutan yang harus "lebih" dari wanita, rasional, dan agresif. Peran laki-laki 
yang ideal adalah sebagai pencari nafkah keluarga, pelindung, "pengayom", dan kepala keluarga (Raharjo, 1995).

Film Kartini merupakan film karya Hanung Bramantyo yang mengangkat kisah inspiratif perjuangan Kartini melawan dominasi maskulin dan belenggu feodalisme di Jepara. Film yang dirilis pada tahun 2017 ini dibintangi oleh Dian Satrowardoyo sebagai Kartini, Christine Hakim sebagai Ngasirah, Deddy Sutomo sebagai Raden Sosroningrat, Acha Septriasa sebagai Roekmini, Ayushita sebagai Kardinah, Reza Rahadian sebagai Sosrokartono, Djenar Maesa Ayu sebagai Raden Adjeng Moeriam, dan berbagai bintang pemeran lainnya. Film ini bercerita tentang kisah Kartini yang dipersiapkan menjadi Raden Ayu kelak ketika dewasa. Hanung Bramantyo menggambarkan Kartini dalam film ini sebagai sosok yang berbeda dengan saudarasaudara perempuannya yang feminim dan penurut. Kartini hidup untuk memperjuangkan kesetaraan bagi semua orang, terutama untuk para perempuan. Kemudian ia mengajak kedua saudarinya, Roekmini dan Kardinah untuk membuat sekolah bagi kaum miskin dan menciptakan lapangan kerja bagi masyarakat Jepara.

Film Kartini menjadi salah satu wujud perlawanan masyarakat modern terhadap konstruksi budaya patriarki di masyarakatmelalui produk komunikasi massa. Film ini juga mengisyaratkan bahwa perempuan dapat berkiprah di sektor publik dan sejajar dengan laki-laki, baik di ranah keluarga, pekerjaan, pendidikan, maupun sosial. Selain menyuarakanperlawanan terhadap budaya patriarki, film karya Hanung Bramantyo ini juga mengangkat potret feodalisme dan pernikahan dini di Jawa pada awal abad 19. Tujuan penelitian ini ada beberapa hal, yaitumendeskripsikan representasi budaya patriarki, perlawanan tokoh Kartini terhadap budaya patriarki;serta reaksi tokoh lain terhadap perlawanan Kartini dalam film Kartini.

\section{METODE PENELITIAN}

Penelitian ini merupakan penelitian deskriptif kualitatif. Penelitian ini menggunakan teori kritik feminis untuk menjabarkan budaya patriarki dan praktik feodalisme dalam film Kartini. Sumber data penelitian ini yaitu sebagai berikut. (1) Film Kartini sebagai objek material penelitian ini dan (2) buku teks dan jurnal-jurnal yang relevan dengan penelitian ini. 
Prosedur pengumpulan data penelitian ini menggunakan teknik melihat/menonton, mencermati, mencatat, dan menganalisis data berdasarkan isi film Kartini. Peneliti melihat/menonton, mencermati, dan menganalisis data dalam film Kartini secara berulang-ulang untuk memahami makna yang terkandung dalam film. Peneliti bertindak sebagai instrumen kunci dalam penelitian ini. Kedudukan peneliti sebagai instrumen kunci berpengaruh pada hasil akhir penelitian karena peneliti berperan sebagai pihak yang menganalisis dan menyimpulkan data yang sudah ditemukan dalam Film Kartini.

\section{HASIL DAN PEMBAHASAN}

\section{Representasi Budaya Patriarki dalam Film Kartini}

Budaya patriarki adalah budaya yang tidak mengakomodasi kesetaraan, keseimbangan, sehingga keberadaan perempuan menjadi tidak penting. Secara umum patriarki dapat didefinisikan sebagai suatu sistem yang bercirikan laki-laki (ayah). Dalam sistem ini, laki-laki yang berkuasa untuk menentukan (Murniati, 2004:81).

Selain itu, budaya patriarki muncul akibat institusi hasil budaya manusia. Melalui pendidikan keluarga, anak laki-laki dididik untuk agresif, pergi ke luar, bermain di luar rumah. Sementara anak perempuan didik untuk memasak, kerasan di rumah, mengerjakan pekerjaan rumah, melayani ayah dan saudara laki-laki. Pendidikan ini akan berakibat laki-laki dilayani dan perempuan melayani (Murniati, 2004:96).

Budaya patriarki masih dianggap wajar dalam masyarakat patriarki. Kekuasaan masing-masing oleh kedua pihak dianggap "wajar"sebab diakui sebagai wewenang masing-masing. Dalam masyarakat patriarki, suami dan istri dianggap wajar bahwa suamilah yang banyak mengambil keputusan dalam macam-macam hal yang bersangkutan dalam kehidupan keluarganya (Sajogyo, 1985:41).

Ketidaksetaraan gender ini sering dikaitkan dengan posisi perempuan yang dianggap tidak menguntungkan. Patriarki sering ditinjau dari posisi laki-laki dan perempuan dalam keluarga. Adanya ketidaksetaraan gender akibat dominasi laki-laki dapat menimbulkan budaya patriarki.Sakina (2017:72) menyatakan bahwa sistem patriarki yang mendominasi kebudayaan masyarakat menyebabkan adanya kesenjangan dan ketidakadilan gender yang mempengaruhi berbagai aspek kegiatan manusia. Lakilaki memiliki peran sebagai kontrol utama di dalam masyarakat, sedangkan perempuan 
hanya memiliki sedikit pengaruh atau bisa dikatakan tidak memiliki hak pada wilayahwilayah umum dalam masyarakat, baik secara ekonomi, sosial, politik, dan bahkan psikologi, termasuk di dalamnya intitusi pernikahan.

Film Kartini banyak menyorot kehidupan perempuan Jawa pada akhir abad ke19 hingga abad ke-20. Dalam film tersebut, digambarkan bagaimana posisi perempuan yang tertindas dalam masyarakat. Sistem adat yang kental dengan ideologi patriarki membuat perempuan Jawa menjadi kaum tertindas. Ideologi patriarki dalam film Kartini digambarkan melalui budaya poligami, keterbungkaman perempuan Jawa, serta diskriminasi dan subordinasi yang dialami oleh perempuan Jawa.

Sebagaimana yang diceritakan dalam film Kartini, budaya Jawa pada abad 19 kental dengan ideologi patriarki. Dari kelas bangsawan hingga rakyat jelata, kaum lelaki di kelas yang sama memiliki nilai yang lebih tinggi dibandingkan perempuan. Perempuan hanya dipandang sebagai 'kanca wingking'yang berkutat pada sektor domestik: seperti dapur, sumur,dan kasur. Pendidikan adalah kemewahan yang tidak bisa dinikmati oleh perempuan Jawa masa itu, termasuk Kartini.Sakina (2017:75) menegaskan bahwa sejarah nasional pun menguak sebuah fakta dimana kaum perempuan tidak diperbolehkan untuk menempuh pendidikan, kecuali perempuan tersebut berasal dari kelas priyayi atau bangsawan.

Sesuai dengan adat istiadat yang berlaku dalam budaya Jawa, Kartini harus dipingit ketika mengalami menstruasi pertama sampai laki-laki bangsawan datang meminangnya. Hatmaja (2019:4) menyatakan bahwa pingitan atau pengantin adalah tradisi pra-nikah biasanya dilakukan sebelum hari pernikahan, calon pengantin tidak boleh keluar rumah maupun bertemu calon suaminya sampai dilangsungkannya ijab kabul. Begitu pula yang dialami Kartini dalam menjalani masa pingitan, Kartini dilarang keluar rumah dan kadipaten. Melakukan pingitan berarti seorang perempuan Jawa disiapkan untuk menjadi Raden Ajeng. Sebagai anak keturunan bupati ningrat, Kartini harus mewariskan darah ningratnya. Tidak hanya Kartini saja yang harus mengalami pingitan, kedua adiknya yakni Roekmini dan Kardinah pun diberlakukan pingitan.

Kartini adalah perempuan yang gemar membaca dan menulis. Ketika kedua adik perempuannya, Kardinah dan Roekmini, berada dalam kamar pingitan bersamanya, Kartini diam-diam menunjukkan buku-buku yang dimilikinya. Di dalam kamar 
pingitan, Kartini melepaskan semua peraturan yang mengekang adik-adiknya ketika di luar, termasuk menunduk, jalan jongkok, dan bicara pelan. Visualisasi tokoh Kartini dan kedua adiknya bisa dilihat pada gambar berikut.

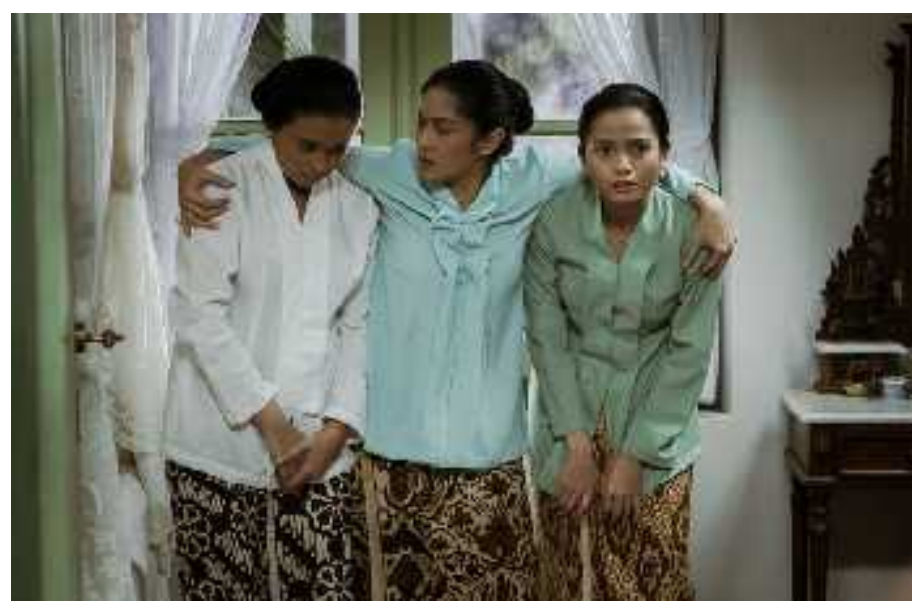

Gambar 1. Visualisasi Tokoh Kartini dan Kedua Adiknya

Setiap orang yang mendukung kesetaraan gender akan berupaya menghapuskan keberadaan budaya patriarki. Hal ini pula yang dilakukan oleh Kartini. Ia mulai mengkritik banyak hal seperti poligami, posisi perempuan dalam kehidupan rumah tangga, dan hak pendidikan bagi perempuan. Poligami pada masa itu seperti sudah menjadi hal yang wajar dan tidak disalahkan. Hingga Kartini menyaksikan hal tersebut menimpa adik perempuannya yang bernama Kardinah. Tidak hanya itu, praktik poligami juga dilakukan oleh Ayahnya.

Perlawanan Kartini terhadap praktik poligami di kalangan bangsawan Jawa akhirnya membawanya pada kesadaran bahwa dirinya sendiri sudah hidup dalam bayang-bayang musuh yang dilawannya. Ia sadar bahwa ia sedang berhadapan dengan lawan yang amat bengis dan kuat, didukung adat-istiadat masyarakat, juga dibenarkan oleh ajaran agama saat itu.

Kartini juga mempermasalahkan bagaimana posisi perempuan dalam kehidupan berumah tangga. Pada masa itu, keputusan keluarga sepenuhnya berada di tangan lakilaki selaku kepala keluarga. Perempuan tidak berhak menyuarakan pendapatnya, keberadaan perempuan saat itu hanya dibutuhkan sebagai pengurus rumah dan pengasuh anak. Hal inilah yang menurut Kartini salah, menurutnya kaum laki-laki seharusnya 
memperlakukan istri mereka dengan lembut, juga memperlakukannya sebagai rekan hidup yang setara posisinya.

Dalam film, Kartini diposisikan sebagai pihak yang harus menaati aturan yang berlaku dalam kalangan bangsawan Jawa, dan seolah hal itu telah menjadi nasib yang harus dialami oleh perempuan dalam budaya Jawa. Pada masa itu, masyarakat Jawa merepresentasikan perempuan sebagai pengabdi bagi laki-laki. Dalam budaya Jawa, laki-laki memegang kekuasaan atas diri perempuan dalam praktik kehidupan.

Perempuan Jawa pada masa itu diposisikan sebagai kaum yang terbelenggu oleh kultur patriarkal. Belenggu tersebut salah satunya bisa dilihat pada karakter tokoh dan adegan yang diperankan oleh beberapa tokoh, salah satunya kakak tiri laki-laki Kartini yang memohon pada ayahnya untuk mengontrol perilaku Kartini supaya tidak menyalahi kodratnya sebagai perempuan.

"Gadis yang pikirannya sudah dicerdaskan, pemandangannya sudah diperluas, tidak akan sanggup lagi hidup di dalam dunia nenek moyangnya." (Kartini)

Dengan dalih kodrat, kakak tiri dan ibu tirinya menentang keinginan Kartini untuk mengajukan beasiswa di Belanda, meskipun ayahnya sendiri sudah memberi ijin. Sebagai anak dari keluarga ningrat, Kartini melihat adanya kultur diskriminatif terhadap perempuan dalam sistem keningratan Jawa. Tidak ada dukungan untuk mengejar pendidikan tinggi hanya karena dirinya seorang perempuan. Perjuangan Kartini adalah perjuangan memerdekakan kaum perempuan dari penindasan dan kebodohan.

\section{Penolakan Tokoh Kartini terhadap Budaya Patriarki}

Pemberontakan Kartini terhadap praktik feodalisme dan patriarki telah tumbuh ketika ia masih kecil. Ia menolak memanggil ibunya (Ngasirah) yang berasal dari kalangan rakyat biasa dengan sebutan "Yu" (panggilan untuk pelayan perempuan di kadipaten). Ia juga enggan disebut sebagai "Raden Ajeng" (sebutan untuk perempuan bangsawan). Kartini kecil bahkan melakukan perlawanan ketika akan dipindahkan ke "rumah depan" dan tinggal bersama ayah dan Raden Ajeng Moeryam. Ia ingin tetap tinggal bersama Yu Ngasirah di rumah belakang dan menolak mennjalani prosesi menjadi seorang raden ajeng. Rumah depan adalah penyebutan untuk tempat tinggal keluarga bangsawan, sedangkan rumah belakang adalah tempat tinggal pelayan kadipaten. Meskipun Yu Ngasirah adalah ibu kandung Kartini, ia harus tetap tunduk pada budaya Jawa dan menghamba pada anak-anaknya yang bergelar bangsawan. Status 
rakyat jelata menjadikannya sejajar dengan pelayan kadipaten lain. Berikut ini visualisasi tokoh Kartini dan Yu Ngasirah.

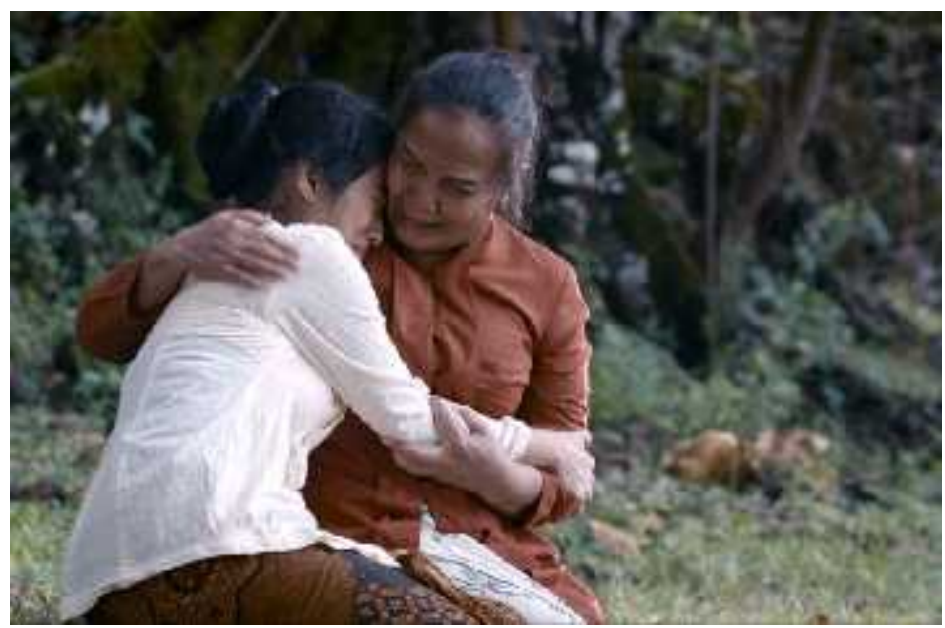

Gambar 2. Visualisasi Tokoh Kartini dan Yu Ngasirah

Menginjak dewasa, perlawanan Kartini terhadap budaya patriarki tergambar melalui keinginannya lepas dari tradisi pingit. Sejak menstruasi pertama, Kartini memang harus menjalani masa pingitan dan dilarang keluar rumah hingga laki-laki bangsawan datang memperistrinya. Wujud penolakan Kartini terhadap budaya patriarki juga tergambar melalui usahanya mengajarkan bahasa Belanda kepada perempuanperempuan dari kalangan rakyat jelata (kawula cilik). Hal ini ia lakukan sebagai upaya mengentaskan kebodohan kaum perempuan Jawa. Usaha Kartini didasari atas pemikiran bahwa pendidikan merupakan satu-satunya cara untuk menghapus ketidakadilan gender.

Kartini kecil yang sudah mengenal dan menikmati budaya sekolah formal tidak mau menerima diskriminasi berdasarkan gender ini. Ia menginginkan hak bersekolah dan melanjutkan sekolah yang sama dengan kakak-kakaknya yang laki-laki. Meskipun Ayah Kartini berpikiran progresif, ia tidak bisa mengabaikan adat pingitan ini. Hal ini bisa dimaknai sebagai betapa kuatnya akar tradisi pingitan ini dalam kehidupan para bangsawan Jawa. Kedudukannya sebagai pejabat daerah dan pemangku adat juga mempengaruhipertimbangannya dalam mengambil keputusan yang berseberangan dengan budaya kaum bangsawan Jawa (Asmarani, 2017:9).

Kartini aktif menyuarakan penderitaan kaum perempuan Jawa masa itu melalui tulisan-tulisannya yang dimuat dalam Jurnal Antropologi dan Bahasa terbitan Lembaga Riset Kerajaan Belanda. Ia memakai nama pena Het Klaveblaad atau daun semanggi 
untuk menutupi identitas aslinya. Kartini bergerilya melawan tradisi leluhur dan stigma masyarakat mengenai hierarkhis gender melalui artikel-artikelnya. Meskipun menuai kecaman dari kalangan bangsawan Jawa, Kartini tidak lantas berhenti menulis. Kedua kakak laki-laki Kartini, Raden Slamet dan Raden Busono, pun ikut menentang pemikiran-pemikirannya. Bahkan mereka memperketat pengawasan terhadap adikadiknya agar tidak dapat lolos dari pingitan. Namun, Kartini tidak kehilangan akal. Ia menulis surat diam-diam kepada Nyonya Ovink Soer agar membantunya lepas dari pingitan. Dengan bantuan Nyonya Ovink-Soer, tulisan-tulisan Kartini dapat dipamerkan di Den Haag dalam rangka memperingati pengangkatan Ratu Willhemnia. Kartini, Roekmini, dan Kardinah juga diberi kesempatan untuk memamerkan produk ukir-ukiran Jepara di Den Haag. Motif ukir-ukiran yang dipamerkan di Den Haag adalah hasil kreasi Kardinah, adik Kartini. Ia mengombinasikan tokoh wayang dalam motif ukirukiran Jepara. Pesanan ukir-ukiran Jepara melonjak pesat setelah pameran seni di Den Haag. Pulihnya sektor perekonomian Jepara kala itu tidak lepas dari kiprah Kartini dan kedua adiknya.

Menyadari pentingnyaperan perempuan sebagai motor penggerakperekonomian, tumbuh keinginan Kartini untuk melanjutkan pendidikannya. Ia percaya pendidikan bagi kaum perempuan menjadi solusi pengentasan kemiskinan dan ketimpangan gender di Jepara. Hal ini sesuai dengan pernyataan Muhardi (2004:480) mengenaipengaruh keberhasilan pendidikan terhadap perkembangan ekonomi dan sosial masyarakat. Ia menyatakan bahwa pondasi pendidikan yang kokoh dan tepat akan dapat diwujudkan cita-cita mulia suatu bangsa dalam berbagai sektor dan aspek kehidupan termasuk kedisiplinan, etos kerja, nilai, dan moral suatu bangsa.

Menyadari pentingnya peran perempuan dalam kehidupan ekonomi dan politik, Kartini mengajukan beasiswa kepada pemerintah kolonial Belanda agar bisa meneruskan pendidikannya dan membantu perempuan Jawa memperoleh hak-haknya. Namun, sebelum pemerintah kolonial Belanda menyetujui pengajuan beasiswanya, Kartini telah lebih dahulu dipinang oleh Bupati Rembang. Ia terpaksa merelakan keinginannya pergi ke Belanda untuk melanjutkan pendidikan. Sebelum mengiyakan pinangan Bupati Rembang, Kartini sempat meminta syarat kepada calon suaminya, yaitu sebagai berikut. 1) tidak mencuci kaki calon suaminya, Kanjeng Adipati Joyodingrat, ketika di pelaminan; 2) tidak dibebani pranata sopan santun yang rumit; 3) 
diperlakukan sebagai orang biasa; 4) Adipati Joyodiningrat harus membantunya mendirikan sekolah bagi perempuan dan orang miskin; dan 5) Yu Ngasirah, ibu kandungnya, harus dipanggil dengan sebutan Mas Kanjeng serta ditempatkan di rumah depan.

Menurut konsep level realita yang dikemukakan oleh John Fiske dalam The Television of Codesdari, obyek audio visual dapat diuraikan sebagai kode-kode sosial dalam film. Level realita merupakan tampilan secara tersurat keadaan dalam film meliputi; penampilan (appearance), pakaian (dress), riasan (make-up), lingkungan (setting), gaya berbicara (speech), dan ekspresi yang terdapat dalam film Kartini. Analisis level realita dalam Film Kartini nampak pada penolakan Kartini mencuci kaki suaminya di pelaminan. Penolakan Kartini merepresentasikan keinginannya untuk disejajarkan dengan laki-laki. Dalam hal ini, mencuci kaki suami melambangkan kedudukan perempuan yang lebih rendah daripada laki-laki dalam keluarga. Selain itu, Kartini hanya menggunakan riasan sederhana ketika acara pernikahannya, berbeda dengan kakak dan adiknya yang menggunakan paesan dan aksesoris pengantin Jawa. Visualisasi Kartini yang menggunakan riasan sederhana ketika menikah melambangkan keinginannya melepas stereotip perempuan sebagai simbol kecantikan dan keanggunan.

Perjuangan Kartini melawan budaya patriarki dan feodalisme tidak berhenti setelah ia menyandang status istri Kanjeng Adipati Joyodiningrat, Bupati Rembang. Justru dengan dukungan suaminya, Kartini bisa membangun sekolah perempuan di pendopo Kadipaten Rembang. Ia juga tetap aktif menuangkan pemikiran-pemikirannya tentang emansipasi dan pendidikan bagi kaum perempuan melalui artikel dan suratsuratnya. Surat-suratnya kemudian dibukukan dengan judul Door Duiternis Tot Licht atau Habis Gelap Terbitlah Terang.

\section{Reaksi Tokoh Lain terhadap Perlawanan Kartini}

Usaha Kartini menghapus budaya patriarki mendapat dukungan dari Raden Kartono Sosroningrat, Romo Ario Sosroningrat, Nyonya Ovinksoer, dan sahabat penanya dari Den Haag, Stella. Melalui Nyonya Ovinksoer dan Stella, Kartini memperoleh sumbangan pemikiran dan kesempatan untuk mengasah kemampuan menulisnya. Ia juga ikut andil memperkenalkan batik Jepara ke pameran seni di Den Haag. 
Raden Kartono merupakan tokoh awal dalam Film Kartini yang tampak mendukung usaha Kartini untuk lepas dari pingitan. Ia memperkenalkan saudarinya itu pada pentingnya literasi dan pendidikan bagi kaum perempuan. Raden Kartono juga memotivasi adiknya untuk memperkaya diri dan memperluas wawasan dengan membaca, meskipun ia sedang menjalani pingitan ketika itu. Wujud dukungan Raden Kartono terhadap cita-cita adiknya nampak pada kutipan dialog berikut ini.

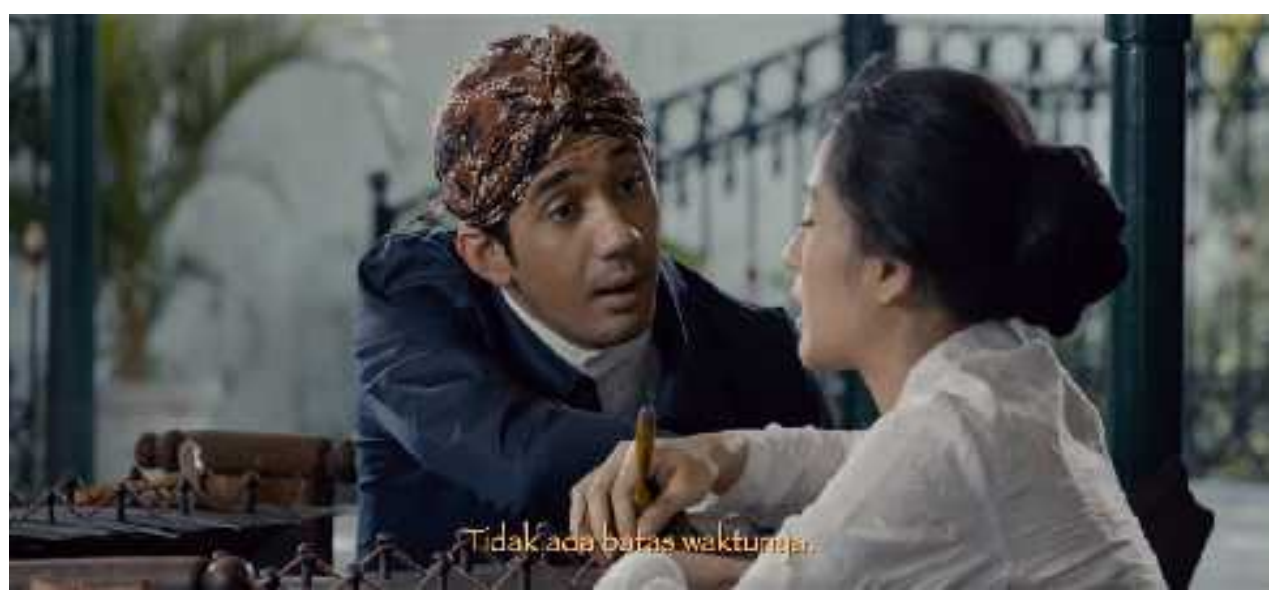

Gambar 3. Dulungan Kartono terhadap Cita-Cita Adiknya

"Tubuh bisa hancur ditelan tanah atau dibakar di atas kayu bakar, ananging pikiranmu tidak ada batas waktunya." (Kartono dalam film Kartini (2017).

Begitu pula dengan Romo Ario Sosroningrat, ia memberikan kesempatan kepada putri-putrinya untuk mengembangkan diri dan mengasah keterampilan mereka. Ia bahkan mengizinkan Kartini dan kedua adik perempuannya mengunjungi Nyonya Ovink Soer untuk belajar menulis atau sekadar berbincang tentang kiprah perempuan Eropa di era modernitas.

Berbeda dengan Kartono dan Romo Ario Sosroningrat, Raden Ayu Moeryam, Raden Slamet, dan Raden Busono justru menentang cita-cita dan keinginan Kartini untuk membebaskan kaum perempuan dari tatanan nilai-nilai patriarki dan feodalisme. Mereka menganggap gagasan-gagasan Kartini tentang hak-hak perempuan telah mencoreng nama leluhur dan melukai budaya Jawa. Meskipun menerima perlakuan represif dari kedua kakak dan ibu tirinya, Kartini, Kardinah, dan Roekmini justru semakin gencar melakukan perlawanan terhadap budaya patriarki dan feodalisme yang memasung ruang gerak perempuan dan hak-hak rakyat kecil. 
Menjelang akhir film Kartini, Raden Ajeng Sulastri muncul sebagai salah satu pendukung cita-cita Kartini setelah dimadu oleh suaminya, Raden Cokro. Kemunculan tokoh Sulastri di akhir film mempengaruhi pendirian ibu kandungnya, Raden Ajeng Moeryam, serta kedua kakak laki-lakinya. Hadirnya tokoh Sulastri di penghujung film Kartini juga menguatkan kesan penderitaan perempuan Jawa terhadap praktik poligami dan dominasi kaum laki-laki di keluarga.

\section{KESIMPULAN}

Berdasarkan pemaparan hasil penelitian di atas, maka kesimpulan penelitian ini adalah sebagai berikut.

1. Representasi budaya patriarki dalam film Kartini nampak dalam tatanan nilai-nilai budaya Jawa yang mengharuskan perempuan bangsawan menjalani masa pingitan, perempuan tidak memilik hak atas pendidikan sebagaimana laki-laki apalagi berkarier di ranah politik dan perekonomian, perempuan Jawa diwajibkan mengurus sektor domestik (urusan rumah tangga, melayani suami, dan lain-lain).

2. Penolakan Kartini terhadap budaya patriarki ditunjukkan melalui sikapnya yang membangkang dan menentang tatanan nilai-nilai Jawa, terutama adat Jawa yang mengungkung dan merendahkan martabat perempuan. Wujud penolakan Kartini terhadap praktik patriarki juga tergambar melalui syarat-syarat yang ia ajukan kepada calon suaminya, Bupati Rembang.

3. Dalam upaya melawan budaya patriarki, Kartini didukung oleh kakaknya, Raden Kartono, serta Raden Ario Sosroningrat. Ia didukung untuk membebaskan pemikiran-pemikirannya dan lepas dari budaya pingit. Sedangkan reaksi Raden Ajeng Moeryam, Raden Slamet, dan Raden Busono jelas bertolak belakang dengan cita-cita Kartini karena mereka menganggap budaya Jawa adalah warisan leluhur yang harus dijaga.

\section{DAFTAR PUSTAKA}

Alkhajar, E. N. S. dkk. (2013). Film sebagai Propaganda di Indonesia. Forum Ilmu Sosial. (Online). 40 (2): 189-200. (journal.unnes.ac.id)

Anggreni, L. S. (2014). Aktivitas Wanita di Sektor Publik dalam Pemberitaan Surat Kabar. Jurnal Ilmu Komunikasi. (11) 1: 55-66. 
Asmarani. (2017). Perempuan dalam Perspektif Kebudayaan. Sabda Volume. (Online). 12 (1): 7-16. (ejournal.undip.ac.id).

Diani, A. dkk. (2017). Representasi Feminisme dalam Film Maleficent. ProTVP. (Online). (1) 2:139-150. (http://jurnal.unpad.ac.id/protvf).

Hatmaja, F. N. T. (2019). Tradisi Pra Nikah Pingitan Pengantin Perkawinan Adat Jawa dalam Perspektif Hukum Islam (Studi Kasus di Desa Cetan Kecamatan Ceper Kabupaten Klaten). Bachelor's thesis, Fakultas Syariah dan Hukum Universitas Islam Negeri 9UIN) Syarif Hidayatullah.

Muhardi. (2004). Kontribusi Pendidikan dalam Meningkatkan Kualitas Bangsa Indonesia. Mimbar. (Online). (20) 4: 478-492. (ejournal.unisba.ac.id).

Murniati, Nunuk P. (2004). Getar Gender: Perempuan Indonesia dalam Perspektif Sosial, Politik, Ekonomi, Hukum, dan HAM. Magelang: Indonesiatera.

Sajogyo, P. (1985). Peranan Wanita Dalam Perkembangan Masyarakat Desa. Jakarta: CV Rajawali.

Sobur, A. (2013). Semiotika Komunikasi. Bandung: PT. Remaja Rosdakarya.

Sakina, A. i. (2017). Menyoroti Budaya Patriarki di Indonesia. Social Work Journal, 7(1), 71-80. 